\title{
Termination of Antiviral Administration in Chronic Hepatitis B
}

\author{
Edward Muliawan Putera, Iswan Abbas Nusi, Poernomo Boedi Setiawan, Herry Purbayu, Titong \\ Sugihartono, Ummi Maimunah, Ulfa Kholili, Budi Widodo, Husin Thamrin, Amie Vidyani and \\ Muhammad Miftahussurur \\ Department of Internal Medicine, Faculty of Medicine, Universitas Airlangga, Dr. Soetomo General Hospital, Jl. Prof dr \\ Moestopo 47 Surabaya 60132, Indonesia \\ apji@fk.unair.ac.id
}

Keywords: Antiviral, chronic hepatitis b, ALT, VHB DNA, NA..

Abstract: Virus Hepatitis B (VHB) eradication still cannot be achieved under current clinical guidelines due to the typical virus life cycle. Four phases of disease in chronic hepatitis B infection have been used as guidance in preparing therapy indications. Virus suppression with a nucleoside analog (NA) is an important part of chronic hepatitis B therapy, but the high post-termination recurrence rate of NA results in an unlimited duration of therapy. Long-term NA therapy results in various problems such as resistance, reduced adherence, side-effects, and economic burden for patients. The latest findings add to the possibility of larger HBsAg seroconversion after the termination of NA therapy. Various guidelines provide guidance on the termination of NA therapy. It is stated that the termination of NA therapy can be performed using strict surveillance methods for individuals who have undergone antiretroviral therapy after which follows $\mathrm{HBeAg}$ seroconversion, minimal amount of VHB DNA, non-cirrhosis status, and normal ALT levels.

\section{INTRODUCTION}

Four hundred million people worldwide are estimated to have had hepatitis B virus (VHB) in 2008 (WHO, 2015). The prevalence of hepatitis B is higher in developing countries or low-income countries. In Indonesia, the prevalence of hepatitis $\mathrm{B}$ according to basic health research in 2013 is $21.8 \%$ (Trihono, 2013).

Most patients who suffer from VHB will become chronic cases. This will cause problems because VHB will lead to complications of liver cirrhosis and hepatocellular carcinoma (HCC). It has been shown that VHB is one of the carcinogenic substances proven to cause hepatocellular carcinoma. Death rates due to liver cirrhosis and HCC reach 310,000 and 340,000 per year in the United States (Terrault, 2015).

The current hepatitis B virus still cannot be eradicated with available therapies. The role of covalently closed circular DNA (cccDNA) in the pathophysiology of hepatitis $\mathrm{B}$ brings about the impact of difficulty in regard to eradication, and contributes to the high rates of failure and relapse. One effort that can be taken in therapy is to reduce the amount of virus in the blood to as little as possible. The most reliable agent to achieve this is a nucleoside analog (NA). NA therapy is administered over a long period of time and often for life. Therefore, the ways and consequences of chronic hepatitis $\mathrm{B}$ cessation must be considered (EASL, 2012; PPHI, 2012; Sarin, 2016; WHO, 2015; Terrault, 2015).

\section{PATHOPHYSIOLOGY OF HEPATITIS B}

VHB infection has a complex and dynamic course of disease, and may change over time. The course of VHB disease may be affected by host factors (age, sex, race, genetic factors, and immune response), viral factors (replication, genotype, and viral variants), as well as environmental factors (alcohol, aflatoxin, and co-infection with other viruses like HIV). These three factors play an important role in the course of VHB disease (Lok, 2011).

The age and immune status of patients with acute hepatitis $B$ affect the course of the next disease in the patient. Most people with acute infection will achieve perfect resolution of antibodies marked by negative HBsAg markers and 
positive anti-HBs. However, recent findings in regard to sensitive PCR, found in some patients who stated they were "healed", still a very small amount of virus either in the liver or in serum. cccDNA is thought to play a role in this. This explains why reactivation of hepatitis B can still be found in patients with perfect resolution. Failure of the body to achieve full elimination of VHB after being declared "healed" means that the eradication of VHB is still not realistic (McMahon, 2009).

There are four phases in chronic VHB infection: the immune-tolerant phase, the immune clearance phase, the inactive inactivation phase, and the reactivation phase. The first phase of the immunetolerant phase has positive $\mathrm{HBeAg}$ features, high DNA VHB, and normal ALT levels. Usually this phase occurs very briefly in individuals who develop chronic VHB infections, but are experienced by infants who contract perinatal VHB infection for 1030 years of life. Minimal levels of liver damage occur, and prognosis is better in individuals who have seroconversion before the age of 40 . The next phase is the immune clearance phase that has positive $\mathrm{HBeAg}$ features; VHB DNA is still high and fluctuates, and continuous or intermittent ALT elevation is an active inflammatory marker if the patient undergoes a biopsy. ALT flare symptoms do not always exist, and do not correlate with seroconversion rates or decreased levels of VHB DNA. This symptom is more common in men, and contributes to higher rates of cirrhosis and HCC in men. The inactive dispersion phase has characteristics of HBeAg loss, anti-HBe positive, persistent normal ALT, and undetectable DNA VHB. Inflammation and fibrosis are present in liver biopsies of patients in this phase, with a larger percentage with increasing age. Patients can be classified in this phase if there are ALT and VHB DNA tests 3-4 times during the last 12 months indicating inactivity. The last phase, i.e. the reactivation phase is characterized by negative HBeAg, positive anti-HBe, high DNA VHB, persistent or intermittent ALT, and a necroinflammatory liver structure. Most patients undergo this phase at a later age, and after the inactive dispersion phase, but some patients may enter this phase immediately after the initial two phases where $\mathrm{HBeAg}$ is still positive (Dienstag, 2008).

HBsAg clearance may occur spontaneously or with therapy in patients with VHB infection. HBsAg clearance rates are estimated to be about $1 \%, 0.54 \%$, and $0.12 \%$ annually in the United States, Italy and Taiwan, respectively, and occur very rarely in the early phases and occur more frequently in the later stages. The prognosis of patients with HBsAg clearance at 50 years of age is excellent, but cirrhosis or HCC complications can still occur even after HBsAg clearance (Lok, 2011; Manno, 2004; Chu, 2007).

Chronic infection of hepatitis B has a complex and dynamic disease course, and may change over time to become a more serious illness with the risk of liver failure and HCC (McMahon, 2009).

\section{INDICATIONS OF CHRONIC HEPATITIS THERAPY}

Indication of therapy in chronic hepatitis B is determined by the combination of four criteria of serum VHB DNA, HBeAg status, ALT values, and histological features of the liver (PPHI, 2012).

The latest indication of therapy is according to the 2015 Asian-Pacific Association for the Study of the Liver (APASL). APASL recommends starting VHB therapy in patients with ALT $\geq 2$ times the normal limit, and VHB DNA $\geq 20,000$ $\mathrm{IU} / \mathrm{mL}$ if $\mathrm{HBeAg}$ is positive and $\geq 2,000 \mathrm{IU} / \mathrm{mL}$ if $\mathrm{HBeAg}$ is negative. Patients with advanced fibrosis or cirrhosis and VHB DNA $\geq 2000 \mathrm{IU} / \mathrm{mL}$ with ALT levels of any kind are recommended for therapy. A 3-6 month observation is recommended for therapeutic needs. This therapy indication is the same for repeat therapy. Special conditions for therapy recommended by APASL are pregnant women with VHB DNA > 2,000,000 IU/mL for treatment in the third trimester. HIV-infected patients with HBV DNA > 2,000 IU/mL and/or severe (moderate-severe) fibrosis or necroinflammation are indicative of anti-HBV therapy. Patients with positive HBsAg who will undergo chemotherapy or immunosuppressive therapy, prophylactic therapy with lamivudine, entecavir or tenofovir are advised to be given these up to six months after the end of treatment. Patients, who will undergo organ transplantation with detectable HBV DNA in the blood, should also be given antinucleosides and HBIg. Recommendations from the Indonesian hepatology organization recommend the same indication of therapy with APASL (PPHI, 2012; Sarin, 2016).

In comparison, we can see some guidance from the world's leading hepatology organizations such as the WHO, AASLD and EASL. The WHO recommends therapy prioritization for VHB for all adults, adolescents, and chronic CHB (or cirrhosis based on an AST to platelet ratio index [APRI] > 2) and should be treated regardless of ALT level, 
HBeAg status, or level of VHB DNA. Therapy is also recommended for all adults with chronic VHB infection without clinical evidence of cirrhosis (or an APRI score $\leq 2$ ), aged over 30 years old, have persistently abnormal ALT levels, and evidence of high VHB replication (VHB DNA > 20,000 IU/mL), regardless of $\mathrm{HBeAg}$ status. The recommendation of the AASLD is antiviral therapy to be given to chronically infected adult VHB individuals with an active immune status, with the definition of an ALT increase $>2$ times the normal limit or evidence of a significant pathological change, and an increase in VHB DNA above $2,000 \mathrm{IU} / \mathrm{mL}$ for $\mathrm{HBeAg}$ negative or above 20,000 for positive HBeAg. The AASLD recommends antiviral therapy for groups of adults aged over 40 with normal ALT and an increase in HBV DNA above $1,000,000 \mathrm{IU} / \mathrm{mL}$ and in liver biopsy there appearing significant or moderate to severe nephrotic fibrosis or inflammation. Then the EASL also recommends patients with chronic VHB infection with $\mathrm{HBeAg}$ positive and $\mathrm{HBeAg}$ negative with ALT more than 2 times the normal limit and VHB DNA above $20,000 \mathrm{IU} / \mathrm{mL}$ to undergo therapy without liver biopsy.

Patients with compensated cirrhosis and detectable VHB DNA should start therapy despite having normal ALT. Patients with decompensated cirrhosis and detected VHB DNA require urgent antiviral therapy with a NA due to significant clinical improvements associated with viral replication control (EASL, 2012; Terrault, 2015; WHO, 2015).

\section{THERAPY OF CHRONIC HEPATITIS B}

The following describes two types of agents for chronic hepatitis B therapy along with a comparison of the characteristics of each agent (Table 1).

IFN has antiviral and immunomodulatory activity. Long-term follow up of patients treated with IFN showed that responders had a reduced incidence of cirrhosis and HCC and increased survival rates compared with nonresponders. PEG-IFN has surpassed the conventional IFN for administration only once a week, and has a higher success rate (Zonneveld, 2004).

Among $\mathrm{HBeAg}$ positive patients, the most reliable predictor of therapeutic response for seroconversion is ALT levels prior to treatment. Other predictable predictors include low VHB DNA, and infection with VHB genotype A or B. Among $\mathrm{HBeAg}$ negative patients, significant reductions in HBsAg titers or low
HBsAg titers at week 12 are associated with a good virological response rate (Rijckborst, 2010).

The most common side-effect of IFN is flulike illness. Other side-effects include body weakness, anorexia, hair loss, emotional instability, bone marrow suppression, and recurrence of autoimmune diseases. IFN is contraindicated in patients with decompensated cirrhosis because of the risk of sepsis and worsening liver failure. IFN should also not be given to patients with acute HCV-related liver failure or severe exacerbations of chronic hepatitis B. However, IFN has been shown to be safe in carefully selected compensated cirrhosis patients (laboratory results describing normal liver function and no proven portal hypertension) (Buster, 2007).

The approved dose for PEG-IFN- $\alpha 2 \mathrm{a}$ is $180 \mu \mathrm{g}$ per week, with subcutaneous administration. PEGIFN- $\alpha 2 \beta$ has been approved for chronic hepatitis B therapy in many countries other than the United States. Doses for PEG-IFN- $\alpha 2 \beta \quad(0.5-1.5 \mu \mathrm{g} / \mathrm{kg}$ body weight per week) have been used in various clinical trials. Interferon therapy refers to decreased levels of VHB DNA and quantitative HBsAg levels at 12 weeks and 24 weeks; if the decrease in VHB DNA levels is less than 2 logs or there is a decrease in quantitative $\mathrm{HBsAg}<20,000 \mathrm{IU} / \mathrm{mL}$, interferon therapy is unresponsive and can be stopped (Terrault, 2015).

Table 1: Comparison of interferon and nucleoside analog characteristics (PPHI, 2012).

\begin{tabular}{|c|c|c|}
\hline & Interferon (IFN) & NA \\
\hline Therapy duration & $\begin{array}{l}\text { Restricted } \\
\text { (maximum } \\
48 \text { weeks) }\end{array}$ & No \\
\hline $\begin{array}{l}\text { Way of } \\
\text { administration }\end{array}$ & $\begin{array}{l}\text { Subcutaneous } \\
\text { injection }\end{array}$ & $\begin{array}{l}\text { Oral once } \\
\text { per day }\end{array}$ \\
\hline $\begin{array}{l}\text { Can be used } \\
\text { for } \\
\text { decompensated } \\
\text { cirrhosis } \\
\end{array}$ & No & Yes \\
\hline Minimal side-effects & & Many \\
\hline $\begin{array}{l}\text { The ability to } \\
\text { suppress DNA } \\
\text { VHB in one year }\end{array}$ & $\begin{array}{l}\text { Slightly } \\
\text { lower }\end{array}$ & $\begin{array}{l}\text { Slightly } \\
\text { higher, use } \\
\text { for more than } \\
\text { one year will } \\
\text { improve } \\
\text { this value }\end{array}$ \\
\hline $\begin{array}{l}\mathrm{HBeAg} \\
\text { seroconversion } \\
\text { ability in one } \\
\text { year } \\
\text { (on } \mathrm{HBeAg} \\
\text { positive) }\end{array}$ & $\begin{array}{l}\text { Slightly } \\
\text { lower }\end{array}$ & $\begin{array}{l}\text { Slightly } \\
\text { higher, use } \\
\text { for more than } \\
\text { one year will } \\
\text { improve } \\
\text { this value }\end{array}$ \\
\hline
\end{tabular}




\begin{tabular}{lll}
\hline $\begin{array}{l}\text { The ability of } \\
\text { seroconversion } \\
\text { HBsAg in one } \\
\text { year }\end{array}$ & Higher & $\begin{array}{l}\text { Lower, can } \\
\text { match the use } \\
\text { for more than } \\
\text { one year }\end{array}$ \\
\hline $\begin{array}{l}\text { Biochemical } \\
\text { response }\end{array}$ & Balance & Balance \\
\hline $\begin{array}{l}\text { Histopathologic } \\
\text { response }\end{array}$ & Balance & Balance \\
\hline Resistance & Not found & $\begin{array}{l}\text { High enough } \\
\text { for some } \\
\text { types }\end{array}$ \\
\hline $\begin{array}{l}\text { Long-term } \\
\text { response }\end{array}$ & $\begin{array}{l}\text { Tend to } \\
\text { improve if } \\
\text { the target } \\
\text { therapy is } \\
\text { reached }\end{array}$ & $\begin{array}{l}\text { Quite often } \\
\text { rele is a } \\
\text { relapse when } \\
\text { therapy is not } \\
\text { continued } \\
\text { long term }\end{array}$ \\
\hline
\end{tabular}

The five NAs used in various guides can be divided into three groups: 1-nucleoside (lamivudine and telbivudine), acyclic phosphonic nucleosides (adefovir dipivoxil and tenopovir disoproxyl), and deoxyguanosine (entecavir) analogs. When entering the hepatocyte nucleus, the VHB DNA is transformed into double-stranded DNA often referred to as cccDNA. This cccDNA acts as a template for pregenomic RNA transcription and messenger RNA. Pregenomic RNA is transversely transcribed into VHB DNA in the hepatocyte cytoplasm. VHB polymerase is divided into several domains, i.e. protein terminals, spacer, POL / RT and RnaseH. The domain POL/RT functions as an inverted transcriptase and as a DNA polymerase. The NA currently employs primers by inhibiting the reverse transcription of the band pregenomic VHB RNA to the first strand of VHB DNA. This agent has no direct inhibitory effect on cccDNA; therefore, VHB relapse is often encountered when NA therapy is discontinued (Lok, 2011).

Among HBeAg positive patients, high ALT levels prior to therapy are the strongest predictors of treatment response. For patients with negative $\mathrm{HBeAg}$, there is no consistent predictor of the therapeutic response. Unlike IFN therapy, the virological response to NAs is similar among all major VHB genotypes (Chang, 2010).

NAs for VHB are given orally, one pill once a day; the dose of all NAs used should be adjusted in patients with impaired renal function. NAs for VHB can be well tolerated by the patient. Adefovir and tenofovir are reported to be associated with nephrotoxic effects, which cause elevated serum creatinine in 3\% of patients after 3-5 years of ongoing therapy. Other effects associated with the kidneys are renal tubular dysfunction and Fanconi syndrome. Tenofovir is also reported to reduce bone mineral density, especially in children. Telbivudine can cause myopathy and peripheral neuropathy, especially if used in combination with PEG-IFN. In a series of cases, entecavir was associated with lactic acidosis in patients with severe liver dysfunction. These data indicate that although NAs for VHB are reported to have excellent short-term safety, the long-term safety of some of these drugs is still frequently debated (Lange, 2009).

\section{TIMES FOR TERMINATION OF NUCLEOSIDE ANALOG THERAPY}

Treatment with conventional interferon is given with limited duration and varies between 4-6 months in patients with positive $\mathrm{HBeAg}$ and up to a year in patients with negative $\mathrm{HBeAg}$. Peg-IFN is given for the duration of one year. Nucleoside analog therapy is administered for longer periods of time than interferons and guidelines have different end points regarding discontinuation of VHB therapy (Lok, 2011). The WHO recommends nucleoside analog therapy in cirrhotic patients with APRI $>2$ scores to be given lifetime therapy and should not be discontinued due to reactivation risk, which will cause severe-acute on chronic liver damage. The termination of nucleoside analog therapy may be considered in individuals with clinical evidence of no cirrhosis or with APRI scores $\leq 2$ in adults, but may be closely followed for reactivation events, and if there is evidence of $\mathrm{HBeAg}$ have lost with seroconversion to anti-HBe (in individuals initially $\mathrm{HBeAg}$ positive) then treated for one additional year after seroconversion, and if there is evidence of normal ALT levels having persisted for the last 6-12 months, and if persistent HBV DNA is undetectable. If there is no VHB DNA facility, treatment discontinuation may be considered in individuals with persistent missing HBsAg who have had additional therapy for one year after, regardless of $\mathrm{HBeAg}$ status (WHO, 2015).

Recommendations from the AASLD suggest that individuals with positive $\mathrm{HBeAg}$ without cirrhosis who have been seroconverted to anti-HBe with nucleoside analog therapy may discontinue VHB therapy after consolidation therapy for 12 months with evidence of normal ALT levels and VHB DNA not persistently detected during consolidation. Monitoring every three months during the first year is required for recurrent 
viremia, ALT increment, seroreversion, and clinical decompensation. The AASLD recommends VHB therapy with lifelong nucleoside analogs for individuals with cirrhosis and positive $\mathrm{HBeAg}$, although seroconversion has been found to be antiHBe. This is due to the potential for clinical decompensation and death. The AASLD recommends lifelong VHB therapy in individuals with negative HBeAg and chronic VHB infection with an active immune status, especially if there is evidence of cirrhosis (Terrault, 2015).

The ultimate goal of therapy with NAs according to the EASL, in patients with positive $\mathrm{HBeAg}$ is seroconversion to anti-HBe, VHB DNA $<2,000$ $\mathrm{IU} / \mathrm{mL}$, normal ALT, and even loss of HBsAg. Therapy may be discontinued 12 months after seroconversion to anti-HBe.

In certain individuals after seroconversion, they cannot maintain a virological or serological response. Nucleoside analog therapy may be continued until the loss of HBsAg with or without anti-HBs, especially in patients with severe cirrhosis. HBsAg is recommended to be reviewed 12 months after seroconversion to anti-HBe. Patients with compensated cirrhosis should continue nucleoside analog therapy for life. Cessation of therapy may be considered in compensated cirrhosis patients with positive $\mathrm{HBeAg}$ who have undergone 12 months of consolidation therapy after seroconversion to anti$\mathrm{HBe}$ or loss of HBsAg and seroconversion to antiHBs. Patients with cirrhosis with negative $\mathrm{HBeAg}$ may discontinue VHB therapy if there is evidence of HBsAg loss and seroconversion to anti-HBs. Patients with decompensated cirrhosis should continue nucleoside analog therapy for life and be prepared for liver transplantation. VHB therapy in cases of decompensated cirrhosis may improve liver function, and in patients with advanced cirrhosis, it may reduce the risk of recurrent post-transplant VHB (EASL, 2012).

According to the APASL in 2015, for patients with positive $\mathrm{HBeAg}$, therapy can be discontinued when $\mathrm{HBeAg}$ seroconversion and VHB DNA can be maintained for at least 12 to 36 months. In $\mathrm{HBeAg}$ negative patients, discontinuation can be considered in patients who lose HBsAg and undergo one additional year of consolidation therapy (three years more recommended), and if there is evidence of undetectable VHB DNA for two years with three examinations within six months (Sarin, 2016).

PPHI provides criteria for discontinuation of nucleoside analog therapy in patients who are $\mathrm{HBeAg}$ positive of HBeAg seroconversion with undetectable VHB DNA for at least 12 months. In patients who are
HBeAg negative, therapy can be discontinued when VHB DNA is undetectable at three checks at intervals of six months. HBeAg, ALT, and VHB DNA examinations are performed monthly in the first three months after the therapy is discontinued. Then, it is continued every three months for a year. If there is no recurrence, checks are performed every three months in cirrhotic patients and every six months for non-cirrhosis (PPHI, 2012).

\section{THE IMPACT OF TERMINATION OF NUCLEOSIDE ANALOG THERAPY}

NAs have an important role in the suppression of VHB DNA titer, with a mean of $71 \%$ of patients being able to attain undetectable DNA VHB status within the first year and higher with long-term use (Wong, 2011). The termination of NAs that have been consumed by a patient has a high risk of recurrence either biochemically (increased ALT) or viral recurrence (VHB DNA increase), potentially leading to liver failure; $90 \%$ of patients have a viral recurrence within 18 months after the termination of NAs despite the tight monitoring and appropriate guidelines. This adds to the burden of clinical consideration of the physician regarding the termination of NAs. The high rate of recurrence is considered by some guides in the world to make NA therapy a long-term or even lifelong therapy in patients with VHB infection who have had liver cirrhosis (Liu, 2011).

\section{WHY IS NUCLEOSIDE ANALOG THERAPY STOPPED?}

Use of NA drugs is conducted for a long time and medication adherence may decrease with time. The most common reason patients do not take medication is because of forgetting and traveling. Poor adherence can increase the likelihood of viral breakthrough by $42.8 \%$ compared with $3.1 \%$ of patients with good adherence (Kamezaki, 2013).

There has been a lot of NA drug resistance. The use of lamivudine after eight years can lead to a resistance rate of $76 \%$. Use of adefovir after five years can lead to a resistance rate of $29 \%$. Early termination of NAs will reduce the resistance to 
them and this is preferred for drugs that still have a good resistance barrier such as entecavir and tenofovir $(1.2 \%$ and $0 \%$ respectively). For the same reason, both drugs are preferred as first-line use of NA for chronic hepatitis B (Fung, 2011).

NA drugs can cause side-effects. Long-term use will increase the risk of these side-effects. Serious toxicities of NA include resistance, bone mineral density reduction, and mitochondrial toxicity that manifest clinically as myopathy, neuropathy, and nephropathy. A systematic review found the risk of nephropathy to be $3-7 \%$ in adefovir use, $4 \%$ nephropathy risk in tenofovir use, with the risk of neuropathy and myopathy of $12.9-17 \%$ (Khungar, 2010). However, another cohort study revealed that these side-effects are not complicated by chronic kidney disease or hip fractures. In hepatitis B patients who consumed NAs compared with non-drinking NAs, a hazard ratio (HR) of 0.79-1.31 for chronic kidney disease and $0.47-1.37$ for hip fracture was found (Wong, 2011).

The price of NAs varies greatly. Lamivudine can be afforded by most patients in both developed and developing countries. However, the use of the newgeneration NAs can increase the burden of NA purchase by up to 10 times per drug gain. Long-term use will burden the patient's financially and decrease adherence (Tantai, 2014).

There have been new ideas put forward by several European and American studies on flare hepatitis B due to the cessation of NAs which resulted in immune reactivation of patients, and potentially lower quantitative HBsAg titers lower than before NAs were discontinued (Siederdissen, 2015). This is indicated by the high expression of programmed cell death-1 (PD-1) in patients with VHB infection resulting in impaired function and number of cluster of differentiation (CD8) cells, which play an important role in intracellular immunity. NA cessation was found to decrease the PD-1 titer in patients and increase the activity of CD8 which is expected to play an important role in HBsAg clearance in patients with VHB infection (Rinker, 2016).

\section{CONCLUSION}

The latest findings add to the possibility of larger HBsAg seroconversion after the termination of NA therapy. There are various guidelines on the termination of NA therapy. It is stated that the termination of NA therapy can be performed using strict surveillance methods for individuals who have undergone antiretroviral therapy which then undergoes $\mathrm{HBeAg}$ seroconversion, minimal amount of VHB DNA, non-cirrhosis status, and normal ALT levels.

\section{REFERENCES}

BUSTER, E. 2007. Peginterferon alpha-2b is safe and effective in $\mathrm{HBeAg}$-positive chronic hepatitis B patients with advanced fibrosis. Hepatology, 46, 388 .

CHANG, T. 2010. Entecavir treatment for up to 5 years in patients with hepatitis $\mathrm{B}$ e antigenpositive chronic hepatitis B. Hepatology, 51, 422.

CHU, C. 2007. HBsAg seroclearance in asymptomatic carriers of high endemic areas: appreciably high rates during a long-term follow up. Hepatology, 45, 1187.

DIENSTAG, J. 2008. Hepatitis B Virus Infection. $N$ Engl J Med, 359, 1486.

EASL 2012. EASL Clinical Practice Guidelines: Management of chronic hepatitis B virus infection. $J$ Hepatol 57, 167.

FUNG, J. 2011. Nucleoside/nucleotide analogues in the treatment of chronic hepatitis B. J Antimicrob Chemother, 66, 2715.

KAMEZAKI, H. 2013. Adherence to Medication Is a More Important Contributor to Viral Breakthrough in Chronic Hepatitis B Patients Treated with Entecavir Than in Those with Lamivudine. Int J Med Sci, 10, 567.

KHUNGAR, V., HAN, S. 2010. A Systematic Review of Side Effects of Nucleoside and Nucleotide Drugs Used for Treatment of Chronic Hepatitis B. Curr Hepatitis Rep, 9, 75.

LANGE, C. 2009. Severe lactic acidosis during treatment of chronic hepatitis B with entecavir in patients with impaired liver function. Hepatology, 50, 2001.

LIU, F. 2011. Poor durability of lamivudine effectiveness despite stringent cessation criteria: A prospective clinical study in hepatitis B e antigennegative chronic hepatitis B patients. Hepatology, $26,456$.

LOK, A. 2011. Hepatitis B, Hoboken, John Wiley \& Sons.

MANNO, M. 2004. Natural history of chronic HBV carriers in Northern Italy: morbidity and mortality after 30 years. Gastroenterology \& Hepatology, 127, 756.

MCMAHON, B. 2009. The Natural History of Chronic Hepatitis B Virus Infection. Hepatology, 49, S45.

PPHI 2012. Konsensus Nasional Penatalaksanaan Hepatitis $B$ di Indonesia, Jakarta, Perhimpunan Peneliti Hati Indonesia/ Indonesian Association for the Study of Liver Disease.

RIJCKBORST, V. 2010. Early on-treatment prediction of response to peginterferon alfa-2a for $\mathrm{HBeAg}$ negative chronic hepatitis B using $\mathrm{HBs} A g$ and $\mathrm{HBV}$ DNA levels. Hepatology 52, 454. 
RINKER, F. 2016. Partially Restored T Cell Responses In HBeAg-Negative Chronic Patients After Stopping NA Therapy. J Hepatol, 64, 388.

SARIN, S., ET AL. 2016. Asian-Pacific Clinical Practice Guidelines on the Management of Hepatitis B: a 2015 update. Hepatol Int, 10, 98.

SIEDERDISSEN, C. 2015. Interruption of nucleos(t)ide analogue therapy for $\mathrm{HBeAg}$-negative Chronic Hepatitis B - a new concept to achieve HBsAg decline? . J Hepatol 62, 572.

TANTAI, N. 2014. A cost-utility analysis of drug treatments in patients with $\mathrm{HBeAg}$-positive chronic hepatitis B in Thailand. BMC Health Serv Res 14, 11.

TERRAULT, N. E. A. 2015. AASLD Guidelines for Treatment of Chronic Hepatitis B. Hepatology, 80, 23.

TRIHONO 2013. Riset Kesehatan Dasar, Jakarta, Badan penelitian dan pengembangan kesehatan.

WHO 2015. Guidelines For The Prevention, Care And Treatment Of Persons With Chronic Hepatitis B Infection. Global Hepatitis Programme, 134.

WONG, D. 2011. Efficacies of One Year Nucleos(t)ide Analogue Therapy in Intrahepatic HBV DNA and Covalently Closed Circular Dna Reduction. J Hepatol 54.

ZONNEVELD, M. 2004. Long-term follow-up of alpha-interferon treatment of patients with chronic hepatitis B. Hepatology, 39, 804. 